\title{
CANONICAL CORRELATION ANALYSIS OF THE CAREER ATTITUDES AND STRATEGIES INVENTORY AND THE ADULT CAREER CONCERNS INVENTORY
}

\author{
CHARLENE C LEW \\ Gordon Institute for Business Science \\ University of Pretoria \\ GIDEON P DE BRUIN \\ Programme in Industrial Psychology \\ Department of Human Resource Management \\ University of Johannesburg \\ gpdb@rau.ac.za
}

\begin{abstract}
This study investigated the relationships between the scales of the Adult Career Concerns Inventory (ACCI) and those of the Career Attitudes and Strategies Inventory (CASI). The scores of 202 South African adults for the two inventories were subjected to a canonical correlation analysis. Two canonical variates made statistically significant contributions to the explanation of the relationships between the two sets of variables. Inspection of the correlations of the original variables with the first canonical variate suggested that a high level of career concerns in general, as measured by the ACCI, is associated with high levels of career worries, more geographical barriers, a low risk-taking style and a non-dominant interpersonal style, as measured by the CASI. The second canonical variate suggested that concerns with career exploration and advancement of one's career is associated with low job satisfaction, low family commitment, high work involvement, and a dominant style at work.
\end{abstract}

Key words

Career concerns, career strategies, Adult Career Concerns Inventory, Careeer Attitudes and Strategies Inventory

The close of the 20th century has seen many changes in the world of work that necessitate self-asserting adaptive behavior from the modern worker (Bridges, 1995; Hall \& Mirvis, 1995; Fourie \& Van Vuuren, 1998). If ever there has been a need for a clear understanding of the content and processes of adult vocational adjustment it is now. Career counselors may be increasingly confronted with adult clients who need assistance with career related decisions. Although psychological measures of abilities, interests, values and personality traits may provide useful information when working with such adults, one often will need to take a broader approach where aspects such as work adjustment, promotion, geographical barriers, family commitments, interpersonal difficulties and the clients' developmental stage are taken into account. Two psychometric instruments that may be helpful in the career counseling process with adults are the Career Attitudes and Strategies Inventory (CASI; Holland \& Gottfredson, 1994) and the Adult Career Concerns Inventory (ACCI; Super, Thompson \& Lindeman, 1988). It is the purpose of this article to examine the relationships between the scales of these two instruments by means of a canonical correlation analysis. In the following paragraphs the underlying theory and research related to the CASI and the ACCI will be discussed.

\section{The Career Attitudes and Strategies Inventory}

According to Gottfredson (1996a) the CASI was developed as a measure of several facets of career status. He defined career status as the summary of a person's vocational adjustment. The facets thereof include among other things, level of work performance, job satisfaction, career attainment, economic welfare, and vocational identity (Gottfredson, 1996a). Note that the different facets are not necessarily correlated and there is no unifying theoretical thread running through the different facets. Rather, the facets of career status included in the CASI represent attitudes, strategies, styles and barriers that may be helpful in understanding the forces that impact on an individual's career. In this regard Gottfredson stated that the authors of the CASI "... sought direct measures of and explanations for career status, rather than making or testing inferences based on psychological or sociological processes" (p. 364).

Various theoretical perspectives strive to explicate the process of adult vocational adjustment and career status. According to $\mathrm{L}$. Gottfredson's (1981) perspective, circumscription and compromise characterize determines career status. However this theory has not found full support in research (Swanson, 1992; Osipow \& Fitzgerald, 1996). Dawis and Lofquist's (1984) theory of work adjustment defines career status in terms of satisfaction, performance and stability as a result of person-environment correspondence. In similar vein, Holland's $(1985,1997)$ theory of vocational choices indicates how congruence between personality and work environment affects career status.

Holland and Gottfredson (1994) aimed to broaden the understanding of the career status meta-construct, and to explain the attitudes, styles and situations that influence career status, as seen in career stability or change. Examining statements of various people on their vocational adjustment, Gottfredson (1996b) concluded that an understanding of vocational adjustment necessitates a comprehension of career-related strategies and attitudes that enable the individual to deal with modern vocational barriers and challenges. Family responsibilities, demands of geographic mobility and willingness to relocate are examples of the challenges and attitudes that need to be considered in adult career adjustment (Gottfredson, 1996b).

Gottfredson (1996a) regards career status as vocational adjustment, which is a function of both personality and the work environment. In fact, vocational adjustment may be regarded as the core of career status. However, several dimensions underlie vocational adjustment namely levels of performance, persistence, satisfaction (with work, rewards, and interpersonal relationships), economic stability, and vocational identity. Career status should therefore be regarded as an umbrella concept of the core variables of vocational adjustment. In addition to personality and work environment, career status is affected by external factors such as gender, social background, economic conditions and so forth. Person-job congruence and circumstances are secondary influences on career status.

Support for the influence of circumstantial and personality variables of vocational adjustment abound in literature. For instance, research findings show specific positive relations between job involvement and tenure (Lynn, Cao \& Horn, 1996; Rotondo, 1999), performance (Mishra \& Gupta, 1994), organization value commitment (Mayer \& Schoorman, 1999) 
and job satisfaction (Kumar \& Achamamba, 1993; Mortimer \& Lorence, 1989). However, according to Strümpfer, Danana, Gouws and Viviers (1998) personality and situational variables should be regarded as modest predictors of job satisfaction.

It would appear that Holland and Gottfredson's (1994) and Gottfredson's (1996a; 1996b) perspectives are not aimed at replacing previous accounts of the process and content of work adjustment, but rather to add to them. Specifically emphasis is placed on the role of personal and situational influences in vocational adjustment. The need to elucidate the nature of career status and vocational adjustment in terms of external realities eventuated in the development of the Career Attitudes and Strategies Inventory (Holland \& Gottfredson, 1994).

\section{The Adult Career Concerns Inventory}

Super's $(1980,1990)$ theory is one of most influential process theories of vocational adjustment. His life-career rainbow model ascribes vocational adjustment to the need to perform specific developmental tasks at various career stages.

The growth stage (ages four to thirteen) includes tasks of becoming concerned with the future, increasing personal control over one's life, convincing oneself to achieve in school and at work, and acquiring competent work habits and attitudes. The developmental tasks of the exploration stage (age fourteen to twenty four) are crystallising, specifying and implementing one's occupational choice (Super, 1980, 1990).

Adults aged approximately twenty five to forty four encounter tasks of stabilising, consolidating and advancing in vocational positions during the establishment stage. Once careers are established adults become concerned with holding on, keeping up, and innovating in their careers during the maintenance stage. In the final career stage (disengagement) after the age of sixty five, deceleration, retirement planning, and retirement living are common (Super, 1980, 1990). In a study supporting Super's career stage theory, Smart (1998) found that work satisfaction and involvement progressively increases through the exploration, establishment and maintenance stages. In an earlier study Ornstein, Corn and Slocum (1989) found that attitudes of commitment to work, job satisfaction and job involvement of individuals in the establishment and maintenance stages were similar.

Re-exploration and re-establishment occur during the transitions between the different career stages (Super, 1980, 1990). These transitions often occur at the ages of 18, 40, 60 and 70 (Super, Savickas \& Super, 1996). Over and above the re-exploration that takes place between career stages, Super et al. (1988) acknowledge that a change in a person's major field of activity is becoming increasingly common. The tendency of continuous career exploration throughout adulthood was supported by Niles, Anderson and Goodnough (1998) who found that exploratory behaviour may be used to maintain current positions, to focus on retirement or even to become more innovative in a current position.

An adult may even return to earlier stages, explore new career fields, or change positions in existing fields. Unlike the linear career maturation of adolescents, adults need to "recycle" through the various stages. During the periods of recycling, the adult may face the same developmental tasks of each of the different stages, but in different forms.

In accordance with the previously described paradigm that encompasses the person-environment fit models, Super (1957, $1980,1990)$ also recognises the role of several internal and external determinants of vocational adjustment. Super's model of career determinants summarises the influences in career development, and specifically, the personal and situational determinants that impact on the life-career rainbow. The specific situational determinants that are identified, are (a) the social structure, (b) historical change, (c) socio-economic organisation and conditions, (d) employment practices, as well as (e) school, community and family influences. Some personal determinants in careers include (a) awareness, (b) attitudes, (c) interests, (d) needs-values, (e) achievement, (f) general and specific aptitudes and even (g) biological heritage (Super, 1980, 1990).

TABLE 1

INTERCORRELATIONS AND INTERNAL CONSISTENCY RELIABILITY COEFFICIENTS OF THE ACCI AND CASI VARIABLES

\begin{tabular}{|c|c|c|c|c|c|c|c|c|c|c|c|c|c|c|c|c|c|c|c|c|c|}
\hline & A1 & A2 & A3 & A4 & A5 & A6 & A7 & A8 & A9 & A10 & A11 & A12 & C1 & C2 & C3 & C4 & C5 & C6 & C7 & C8 & C9 \\
\hline A1 & - & & & & & & & & & & & & & & & & & & & & \\
\hline A2 & 82 & - & & & & & & & & & & & & & & & & & & & \\
\hline $\mathrm{A} 3$ & 74 & 77 & - & & & & & & & & & & & & & & & & & & \\
\hline A4 & 59 & 67 & 67 & - & & & & & & & & & & & & & & & & & \\
\hline A5 & 53 & 61 & 63 & 75 & - & & & & & & & & & & & & & & & & \\
\hline A6 & 54 & 64 & 61 & 72 & 79 & - & & & & & & & & & & & & & & & \\
\hline A7 & 56 & 57 & 60 & 66 & 76 & 75 & - & & & & & & & & & & & & & & \\
\hline A8 & 57 & 62 & 56 & 59 & 65 & 71 & 69 & - & & & & & & & & & & & & & \\
\hline A9 & 57 & 63 & 59 & 59 & 67 & 72 & 70 & 84 & - & & & & & & & & & & & & \\
\hline A10 & 39 & 39 & 40 & 46 & 48 & 47 & 58 & 44 & 42 & - & & & & & & & & & & & \\
\hline A11 & 26 & 27 & 27 & 38 & 37 & 32 & 45 & 34 & 35 & 55 & - & & & & & & & & & & \\
\hline A12 & 37 & 38 & 36 & 42 & 41 & 42 & 46 & 40 & 42 & 46 & 75 & - & & & & & & & & & \\
\hline C1 & -24 & -22 & -18 & -12 & -09 & -16 & -12 & -13 & -15 & -17 & -17 & -17 & - & & & & & & & & \\
\hline $\mathrm{C} 2$ & 06 & 07 & 07 & 06 & 03 & 13 & 04 & 11 & 16 & -09 & -08 & -02 & 35 & - & & & & & & & \\
\hline C3 & 04 & 06 & 03 & 03 & 02 & 11 & 00 & 08 & 12 & -07 & -08 & -04 & 32 & 94 & - & & & & & & \\
\hline C4 & -08 & -02 & -11 & -12 & -11 & 01 & -10 & 00 & 07 & -18 & -17 & -11 & 11 & 35 & 36 & - & & & & & \\
\hline C5 & 16 & 12 & 21 & 28 & 25 & 23 & 30 & 16 & 11 & 34 & 21 & 20 & -35 & -13 & -20 & -36 & - & & & & \\
\hline C6 & 16 & 08 & 06 & 19 & 10 & 16 & 14 & 13 & 09 & 25 & 14 & 14 & -42 & -22 & -23 & -10 & 36 & - & & & \\
\hline C7 & 07 & 03 & 07 & 07 & 09 & -01 & 12 & -11 & -02 & 17 & 06 & 04 & -11 & -00 & -06 & -02 & 27 & 18 & - & & \\
\hline C8 & 23 & -17 & -28 & -31 & -16 & -19 & -26 & -15 & -09 & -24 & -28 & -29 & 04 & 03 & 07 & 43 & -35 & -06 & -02 & - & \\
\hline C9 & 13 & 07 & 12 & 23 & 12 & 07 & 12 & 02 & 07 & 07 & 19 & 13 & 00 & -01 & -08 & -22 & 26 & -11 & 05 & -27 & - \\
\hline$\alpha$ & 87 & 91 & 87 & 88 & 87 & 84 & 87 & 89 & 90 & 80 & 87 & 90 & 90 & 67 & 71 & 71 & 92 & 97 & 84 & 83 & 76 \\
\hline
\end{tabular}

Note. A1 = Crystallization, A2 = Specification, A3 = Implementation, A4 = Stabilizing, A5 = Consolidating, A6 = Advancing, A7 = Holding, A8 = Updating, A9 = Innovating, A10 = Decelerating, A11 = Retirement Planning, A12 = Retirement Living, C1 = Job Satisfaction, C2 = Work Involvement, C3 = Skill Development, C4 = Dominant Style, C5 = Career Worries, C6 = Interpersonal Abuse, C7 = Family Commitment, C8 = Risk-Taking Style,C9 = Geographical Barriers. Decimal commas are omitted. 
In accordance with Super's $(1980,1990)$ theory career concerns relate to specific developmental tasks that are associated with specific stages in career development. As operationalised by the Adult Career Concerns Inventory (Super, Thompson \& Lindeman, 1988), career concerns may be defined as affective and cognitive interpretation of career tasks during stages of exploration, establishment, maintenance, and disengagement.

\section{The convergence of two perspectives on vocational adjustment}

Considering the two perspectives on vocational adjustment described above, one may already detect similarities, especially pertaining to the determinants of vocational adjustment. One is left however with the question as to how the career development task-related career concerns as operationalised by means of the Adult Career Concerns Inventory relates to career status as operationalised by the Career Attitudes and Strategies Inventory. In this regard it is of theoretical and practical interest to explore how different career stages and substages of the ACCI relate to the career attitudes and concerns of the CASI. The present study sought to find answers to this question by means of a canonical correlation analysis of these two measuring instruments.

\section{METHOD}

\section{Participants}

Participants were 202 adults between the ages of 25 and 48. The majority of the participants (93\%) were in the age group associated with Super's $(1980,1990)$ establishment stage and the remaining $7 \%$ were in the age group associated with the maintenance stage. The participants were mostly recruited from a MBA program in Johannesburg. The remaining participants were recruited via the human resources departments of four different companies. $97 \%$ of the sample was employed fulltime, and the majority was from the field of business, and especially management.

\section{Measuring instruments}

Adult Career Concerns Inventory. The 61-item Adult Career Concerns Inventory measures the concerns of individuals with career development tasks of the exploration, establishment, maintenance, and disengagement stages and their substages. Each of the stages are subdivided into three stages, namely Crystallisation, Specification, and Implementation (Exploration stage); Stabilising, Consolidating and Advancing (Establishment stage); Holding, Updating and Innovating (Maintenance stage); and Decelerating, Retirement Planning and Retirement Living (Disengagement). Respondents rate their level of concern with the developmental tasks ranging from 'no concern' to 'great concern', and also indicate on a single item whether career change is being considered or not (Rounds, 1994). In addition to the above the final item of the instrument has been designed to identify concerns relating to recycling. The career status of the respondent, i.e. whether any career change is eminent or has recently occurred is obtained by this item (Super et al., 1988).

There is empirical evidence of the construct, concurrent and predictive validity of the earlier form of the Adult Career Concerns Inventory (Stout, Slocum \& Cron, 1987). The reliability, construct validity, and internal consistency of the subscales thereof have also been empirically attested (Halpin, Ralph \& Halpin, 1990; Whiston, 1990; Duarte, 1995). Relative to its factor structure, of the assumed Exploration, Establishment, Maintenance, and Disengagement factors, Establishment and Maintenance have merged in a study using principle axis factor analysis (Mahoney, 1986) and Exploration and Establishment have merged in a principle components factor analysis (Duarte, 1995). Smart and Peterson (1994) have also found support for the cross-cultural and construct validity of the instrument.

\section{Career Attitudes and Strategies Inventory}

The 130-item Career Attitudes and Strategies Inventory consists of nine scales: Job satisfaction; Work involvement; Skill development; Dominant style; Career worries; Interpersonal abuse; Family commitment; Risk-taking style; and Geographical barriers. These scales each represent a potential influence on an individual's career, as well as the individual's perception of the influence (Gottfredson, 1996b). In addition to these scales, the answer sheet of the Career Attitudes and Strategies Inventory provides for a career obstacles checklist, according to which specific career-related obstacles may be listed, for instance appearance, physical limitations, lack of money, criminal record, religion and so forth (Holland \& Gottfredson, 1994).

There is still a vast need for studies on the personal and environmental influences on career adjustment. Currently the manual of the Career Attitudes and Strategies Inventory (Holland \& Gottfredson,1994) seems to be one of a few sources of research pertaining to this instrument as it defines career status. The manual reports on the concurrent validity of this questionnaire. Correlations between various scales and some of the Career Attitudes and Strategies Inventory subscales are reported, for instance between the Hoppock's Job Satisfaction Blank (Hoppock, 1935) and the Career Attitudes and Strategies Inventory job satisfaction scale. Correlations between the Career Attitudes and Strategies Inventory scales of career worries, job satisfaction and interpersonal abuse, and a measure of career search abilities may suggest that career stability could be predicted from the Career Attitudes and Strategies Inventory scales. Results also indicate the independence of the various Career Attitudes and Strategies Inventory scales (Gottfredson, 1996b; Holland \& Gottfredson, 1994).

\section{Canonical correlation analysis}

The relations between the 12 subscales of the ACCI and the 9 scales of the CASI were examined by means of a canonical correlation analysis. This analytic method is used to investigate relations among two or more variable sets (Thorndike, 2000). In canonical correlation analysis the variables in each set are combined in such a way as to produce, for each set, a predicted value that has the highest correlation with the predicted value in the other set. Hence, a canonical correlation may be viewed as the product-moment correlation between two weighted composites where the composites of a pair are defined so that they maximise their canonical correlation (Thorndike, 2000, p. 242). The square of the canonical correlation "expresses the proportion of variance in each composite that is related to the other composite of the pair" (Thorndike, 2000, p. 244). The two weighted composites are jointly referred to as a canonical variate.

The variance explained by a canonical variate may be partialled from the original correlation matrix and a second canonical variate may be formed from the residuals. This canonical variate will be orthogonal to the first canonical variate and will always explain less of the variance than the first variate. The process may be repeated until a non-significant canonical variate is found, or when the number of variates are equal to the number of variables in the smaller set.

Canonical correlation analysis was employed to answer the following questions:

a) How many reliable canonical variate pairs are there in the combined ACCI and CASI data set?

b) Along how many dimensions are the 12 ACCI subscales related to the 9 CASI scales?

c) How are the dimensions that relate the ACCI subscales and the CASI scales to be interpreted?

d) How strong is the correlation between variates in a pair? 


\section{RESULTS}

The correlations and reliability coefficients (Cronbach's alpha) of the 12 ACCI subscales and nine CASI scales are presented in Table 1 . Inspection of the reliability coefficients suggests that sufficiently reliable scores were obtained for research purposes. The two sets of variables were subjected to a canonical correlation analysis using BMDP6M. The squared multiple correlations of the variables within the ACCI set ranged between 0,45 and 0,77 . The mean of these squared multiple correlations was 0,69 , suggesting a high level of overlap between the 12 subscales of the ACCI set. Within the CASI set the squared multiple correlations ranged between 0,17 and 0,90 . The mean of these squared multiple correlations was 0,41 , suggesting a moderate level of overlap between the 9 scales of the CASI set.

With all nine canonical correlations included, $\chi^{2}(108)=202.30$, $\mathrm{p}=0,0000$. Removal of the first canonical correlation gave $\chi^{2}$ $(88)=129.19, p=0,0028$. Removal of the second canonical correlation led to a non-significant $\chi^{2}$. Hence, only the first two canonical variates made statistically significant contributions to the explanation of the relations between the ACCI and CASI variables. The first canonical correlation was $0,57 \quad(32 \%$ overlapping variance of the canonical variates) and the second canonical correlation was 0,48 (21\% of overlapping variance of the canonical variates).

TABLE 2

CORRELATIONS OF THE ACCI AND CASI VARIABLES WITH THE FIRST TWO CANONICAL VARIATES

\begin{tabular}{|c|c|c|c|}
\hline & $\begin{array}{c}\text { Canonical } \\
\text { Variate } 1\end{array}$ & $\begin{array}{c}\text { Canonical } \\
\text { Variate } 2\end{array}$ & $\mathbf{h}^{2}$ \\
\hline \multicolumn{4}{|l|}{ ACCI set } \\
\hline Crystallization & $\underline{0,47}$ & $\underline{0,45}$ & 0,42 \\
\hline Specification & 0,29 & $\underline{0,45}$ & 0,29 \\
\hline Implementation & $\underline{0,47}$ & $\underline{0,35}$ & 0,34 \\
\hline Stabilizing & $\underline{0,69}$ & 0,32 & 0,58 \\
\hline Consolidating & $\underline{0,42}$ & 0,04 & 0,18 \\
\hline Advancing & $\underline{0,41}$ & $\underline{0,46}$ & 0,38 \\
\hline Holding & $\underline{0,58}$ & 0,15 & 0,36 \\
\hline Updating & 0,24 & $\underline{0,53}$ & 0,34 \\
\hline Innovating & 0,19 & $\underline{0,55}$ & 0,34 \\
\hline Decelerating & $\underline{0,67}$ & $-0,10$ & 0,46 \\
\hline Retirement Planning & $\underline{0,58}$ & 0,15 & 0,36 \\
\hline Retirement Living & $\underline{0,53}$ & 0,30 & 0,37 \\
\hline \multicolumn{4}{|l|}{ CASI set } \\
\hline Job satisfaction & $-0,23$ & $-\underline{0,36}$ & 0,18 \\
\hline Work involvement & $-0,14$ & $\underline{0,44}$ & 0,21 \\
\hline Skill development & $-0,17$ & $\underline{0,36}$ & 0,16 \\
\hline Dominant Style & $-\underline{0,47}$ & $\underline{0,37}$ & 0,36 \\
\hline Career Worries & $\underline{0,69}$ & $-0,13$ & 0,49 \\
\hline Interpersonal Abuse & $\underline{0,48}$ & 0,14 & 0,25 \\
\hline Family Commitment & 0,33 & $-\underline{0,42}$ & 0,29 \\
\hline Risk-Taking Style & $-\underline{0,78}$ & $-0,19$ & 0,64 \\
\hline Geographical Barriers & $\underline{0,45}$ & 0,08 & 0,21 \\
\hline
\end{tabular}

Note. All values rounded to two decimal places. $\mathrm{h}^{2}=$ proportion of variance of a variable in one set that is explained by the combination of variables in the other set.

Because several of the variables within the two sets were moderately to highly correlated, we interpreted the correlations of the variables with the canonical variates (structure coefficients) rather than the standardized regression weights of the variables in the canonical variates. The standardized regression weight of a variable in a canonical variate reflects the independent contribution of the variable to the composite formed by all the variables in the set, but "a variable may receive a small weight simply because it is highly correlated with another variable in its set, even though both variables have high correlations with the variate" (Thorndike, 2000, p. 252).

With a cutoff correlation of 0,30 , five variables from the CASI set were meaningfully correlated with the first canonical variate (see Table 2), namely Dominant Style $(r=-0,47)$, Career Worries $(r=0,69)$, Interpersonal Abuse $(r=0,48)$, Risk-Taking Style $(r=-0,78)$, and Geographical Barriers $(r=0,45)$. Nine of the 12 variables in the ACCI set were correlated with the first canonical variate, namely Crystallization $(\mathrm{r}=0,47)$, Implementation $(r=0,47)$, Stabilizing $(r=0,69)$, Consolidating $(\mathrm{r}=0,42)$, Advancing $(\mathrm{r}=0,41)$, Holding $(\mathrm{r}=0,58)$, Decelerating $(\mathrm{r}=0,67)$, Retirement Living $(\mathrm{r}=0,58)$, and Retirement Planning $(\mathrm{r}=0,53)$.

Five variables from the CASI set were correlated with the second canonical variate, namely Job Satisfaction $(r=-0,36)$, Work Involvement $(r=0,44)$, Skill Development $(r=0,36)$, Dominant Style $(r=0,37)$, and Family Commitment $(r=-0,42)$. The following variables from the ACCI set were correlated with the second canonical variate: Crystallization $(r=0,45)$, Specification $(\mathrm{r}=0,45)$, Implementation $(\mathrm{r}=0,35)$, Advancing $(\mathrm{r}=0,46)$, Updating $(r=0,53)$, and Innovating $(r=0,55)$.

\section{DISCUSSION}

The aim of this study was to explore the relations between the scales of the ACCI and those of the CASI by means of canonical correlation analysis. Two significant canonical correlations were obtained that jointly explained approximately $51 \%$ of the variance of the two sets of variables.

From the CASI set, Risk-Taking Style (negative) and Career Worries (positive) had the strongest correlations with the first canonical variate. Hence, it appears that an adult with high levels of overall career concerns (ACCI) will also have a low risk-taking style. The risk-taker according to the CASI is someone who, instead of being cautious, may be seen as impulsive, unpredicatable, reckless, and willing to deal with uncertainty. This is associated with traits such as extroversion and openness and negatively related with conscientiousness (Holland \& Gottfredson, 1994). One may therefore infer that cautiousness and conscientiousness is associated with overall career concerns. These ACCI concerns are also strongly correlated with career concerns, in as far as career concerns is equated with anxiety about one's career. Clearly, as a person experiences the concerns relating to the adjustment tasks of the adult career, it will be associated to aversion to change, and a sense of finding work life too difficult or demanding. Career worries are further personified by feelings of anger, envy, insecurity or tenseness (Holland \& Gottfredson, 1994). In other words, this pattern of correlations suggests that individuals with high scores for this variate would be cautious about taking risks in their careers and would perceive their general work-related context as negative or threatening.

Other CASI variables with meaningful correlations with the first variate were Dominant Style (negative), Interpersonal Abuse (positive), and Geographical Barriers (positive). Holland and Gottfredson (1994) define dominant style as the leadership traits of persuasiveness, ambition, decisionmaking and problem-solving skills, as well as forcefulness and being influential. One may therefore infer that individuals with overall adult career concerns are likely to be dominated by others and will try to avoid conflict with others and may be experiencing interpersonal abuse in the workplace. High interpersonal abuse scores have formerly been shown to relate inversely to traits of agreeableness and emotional stability (Holland \& Gottfredson, 1994). 
Overall, it appears that individuals with high scores for this variate would be likely to experience general negative affect regarding their careers and in the work place. Not surprisingly, nine of the 12 ACCI variables correlated with the first canonical variate, suggesting that this variate reflects a general career concerns dimension. The first canonical correlation of 0,57 suggests that individuals with negative career related affectivity tend to be concerned about almost all the stages and substages in Super's model of career development.

The pattern of correlations on the second canonical variate may be summarized as follows: Individuals with high scores on a CASI variate that reflects high work involvement, high skill development, a dominating interpersonal style, low family commitment and low job satisfaction, are likely to obtain high scores on an ACCI variate that reflects concerns about career exploration (crystallization, specification and implementation), stabilizing and advancing one's career, and updating and improving one's career related knowledge and skills. Theoretically exploration occurs between the ages of fourteen and twenty four, where initial career choice becomes increasingly clear and specific and is implemented. Adults between the ages of twenty five and forty four will attempt to remain in the same job for at least a couple of months, while learning to meet job requirements and being somewhat apprehensive about their competencies (stabilizing). Being concerned about moving to a higher position or earning a higher income (advancing), or innovating to maintain one's career is also typical of this adult career stage (Super, 1990). According to the findings, these concerns go hand in hand with high work involvement, which Holland and Gottfredson (1994) define as devotion to one's career. It involves feeling positive about work, taking work home and thinking about work when not at work. It also relates to an attitude of wanting to improve one's performance or skills, the leadership qualities associated with a dominant style and a sense that work responsibilities do not interfere with family commitment. Moreover, these adult career concerns entail low job satisfaction.

In other words, the CASI variables' pattern of correlations with the second canonical variate appears to reflect a commitment to one's career rather than one's family, a desire to improve one's knowledge and skills, a desire to dominate others in the workplace, and a relatively low sense of job satisfaction. The ACCI variables' pattern of correlations suggests that individuals with high scores may be primarily concerned about exploring new career opportunities, improving and developing as workers and advancing in their careers. Individuals with high scores on this variate may be dissatisfied with environments that do not accommodate their desire to advance and to improve and may either attempt to improve their position within their own environment or to find a new working environment that will accommodate their desires.

In summary, the results showed that the relationships between the CASI and the ACCI can be summarized in terms of two dimensions, namely general negative career affectivity and career ascendancy. Individuals high on the first dimension may be expected to experience anxiety in the work place and to prefer stability and predictability with regards to their careers. In contrast, individuals high on the second dimension may be expected to be excitement seekers who thrive on new challenges and who quickly become bored with routine. The canonical correlation analysis showed considerable overlap between the two sets of measures, but each set contributes meaningful unique information. This supports the notion that circumstantial variables may affect the overall career concerns, and ultimately adjustment, of adults. The results suggest that the combination of the ACCI and the CASI may help to paint a rich picture of an individual's career status and career concerns, which may provide useful information in the career counselling context.

\section{REFERENCES}

Bridges, W. (1995). Jobshift: How to prosper in a workplace without jobs. London: Nicolas Brealey Publishing

Dawis, R.V. \& Lofquist, L.H. (1984). A psychological theory of work adjustment: An individual-differences model and its applications. Minneapolis, MN: University of Minnesota Press.

Duarte, M.E. (1995).Career concerns, values and role salience in employed men. The Career Development Quarterly, 43, 338349.

Fourie, C. \& Van Vuuren, L.J. (1998). Defining and measuring career resilience. Journal of Industrial Psychology, 24 (3), 5259.

Gottfredson, G.D. (1996a). Some direct measures of career status: Putting multiple theories into practice. IN M.L. Savickas \& W.B. Walsh, Handbook of career counseling theory and practice ( $\mathrm{p}$ 213-236). Palo Alto, CA: Consulting Psychologists Press.

Gottfredson, G.D. (1996b). The assessment of career status with the Career Attitudes and Strategies Inventory. Journal of Career Assessment, 4, 363-381.

Gottfredson, L.S. (1981). Circumscription and compromise: A developmental theory of occupational aspirations (monograph). Journal of Counseling Psycyology, 28, 545-579.

Hall, D.T. \& Mirvis, H. (1995). The new career contract: Developing the whole person at midlife and beyond. Journal of Vocational Behavior, 47, 269-289.

Halpin, G., Ralph, J. \& Halpin, G. (1990). The Adult Career Concerns Inventory: Validity and reliability. Measurement and Evaluation in Counseling and Development, 22, 196-202.

Holland, J.L. (1997). Making vocational choices: A theory of vocational personalities and work environments (3rd edition). Odessa, FL: Psychological Assessment Resources.

Holland, J.L. \& Gottfredson, G.D. (1994). Career Attitudes and Strategies Inventory: An inventory for understanding adult careers. Odessa, FL: Psychological Assessment Resources.

Hoppock, R. (1935). Job satisfaction. New York: Harper.

Kumar, K.G. \& Achamamba, B. (1993). A comparative study of job satisfaction and job involvement among public and private sector employees. Psychological Studies, 38, 60-72.

Lynn, S.A., Cao, L.T. \& Horn, B.C. (1996). The influence of career stage on the work attitudes of male and female accounting professionals. Journal of Organizational Behavior, $17,135-149$

Mahoney, D.J. (1986). An exploration of the construct validity of a measure of adult vocational maturity. Unpublished doctoral dissertation, Teachers College, Columbia University.

Mayer, R.C. \& Schoorman, F. D. (1998). Differentiating antecedents of organizational commitment: A test of March and Simon's model. Journal of Organizational Behavior, 19, 15-28.

Mishra, P.C. \& Gupta, J. (1994). Performance as a function of employees' motivation and job involvement. Psychological Studies, 39, 8-20.

Mortimer, J.T. \& Lorence, J. (1989). Satisfaction and involvement: Disentangling a deceptively simple relationship. Social Psychology Quarterly, 52, 249-265.

Niles, S.G., Anderson, W.P. \& Goodnough, G. (1998). Exploration to foster career development. The Career Development Quarterly, 46, 288-292.

Ornstein, S., Cron, W.L. \& Slocum, J.W. (1989). Life stage versus career stage: A comparative test of the theories of Levinson and Super. Journal of Organizational Behavior, 10, 117-133.

Osipow, S.H. \& Fitzgerald, L.F. (1996). Theories of career development (4th edition). Boston: Allyn and Bacon.

Rotondo, D. (1999). Individual-difference variables and careerrelated coping. Journal of Social Psychology, 139, 458-471.

Rounds, J. (1994). The Adult Career Concerns Inventory. In J.T. Kapes, M.M. Mastie \& E. A. Whitfield (Eds.), A counselor's guide to career assessment instruments, (pp. 241-272). Alexandria, USA: National Career Development Association. 
Smart, R.M. (1998) Career stages in Australian professional women: A test of Super's model. Journal of Vocational Behavior, 52, 379-395.

Smart, R.M. \& Peterson, C.C. (1994). Super's stages and the fourfactor structure of the Adult Career Concerns Inventory in an Australian sample. Measurement and Evaluation in Counseling and Development, 26, 243-257.

Stout, S.K., Slocum, J.W. \& Cron, W. L. (1987). Dynamics of the career plateauing process. Working paper 97-073, E.L. Cox School of Business, Southern Methodist University, Dallas.

Strümpfer, D.J.W., Danana, N., Gouws, J.F. \& Viviers, M.R. (1998). Personality dispositions of job satisfaction. South African Journal of Psychology, 28, 99-100.

Super, D.E. (1957). The psychology of careers: An introduction to vocational development. New York: Harper and Row.

Super, D.E. (1980) A life-span, life-space approach to career development. Journal of Vocational Behavior, 16, 282-298.

Super, D.E. (1990). A life-span, life-space approach to career development. In D. Brown \& L. Brooks Eds.), Career choice and development: Applying contemporary theories to practice (2nd edition). Palo Alto, CA: Consulting Psychologists Press.

Super, D.E., Savickas, M.L. \& Super, C.M. (1996). In D. Brown \& L. Brooks (Eds.), Career choice and development (3rd edition). San Francisco, CA: Jossey-Bass.

Super, D.E., Thompson, A.S. \& Lindeman, R.H. (1988). Adult Career Concerns Inventory: Manual for research and exploratory use in counseling. Palo Alto, CA: Consulting Psychologists Press.

Swanson, J.L. (1992). Vocational Behavior, 1989-1991: Life-span career development and reciprocal interaction of work and nonwork. Journal of Vocational Behavior, 41, 101-161.

Thorndike, R.M. (2000). Canonical correlation analysis. In H.E.A. Tinsley \& S.D. Brown (Eds.) Applied multivariate statistics and mathematical modeling (pp. 237-263).

Whiston, S.C. (1990). Evaluation of the Adult Career Concerns Inventory, Journal of Counseling and Development, $69,78-80$ 